\title{
SOME RECENT ASPECTS OF ELECTROCARDIOGRAPHY
}

\author{
A. SchotT, M.D.(HeIDELBERG), M.R.C.S. \\ Physician-in-charge, Cardiological Department, Queen Mary's Hospital for the East End, London
}

IT would be ungracious for us as guests of this University not to remind ourselves that, without three great Italians, we might not have electrocardiography as we know it, perhaps no electrocardiography at all: Galvani, Volta and Matteucci (Fig. I). It was Matteucci, Professor of Physics in Pisa, who in 1843 first reported electrical currents in strips of pigeons' heart muscle, a discovery from which the start of electrocardiography may be dated (Fig. 2). Jumping from Pisa to Chicago, and just over a century in time, we arrive at a convenient juncture from which to start our brief survey of some recent developments: the invention in 1949 of intra-cellular recording of electrical potentials by Ling and Gerard. This method, extensively used in experimental cardiology, has demonstrated directly the resting potential across the cell membrane and made it possible to study the action potential in detail (Fig. 3): The rapid depolarization terminating in a momentary reversal of the polarity of the electrical charges across the membrane, corresponding to the $R$ wave in the ECG; the plateau at or about zero potential corresponding to the S-T segment; and repolarization corresponding to the $T$ wave. By studies in patients undergoing cardiac surgery these conditions were shown also to apply to the human heart (Woodbury, Lee, Brady and Merendino, r957; Trautwein, Kassebaum, Nelson and Hecht, 1962). Of the great number of observations one may be mentioned in view of its close relation to clinical medicine. Vagal stimulation and acetylcholine have been shown to produce marked shortening of the repolarization phase in the mammalian atrium. As it is known that the effect of digitalis is partly mediated by the vagus, and that digitalis glycosides and acetylcholine potentiate one another (Perry and Reinert, 1954; McEwen, 1956), we have now a better understanding of the mechanism underlying the conversion by digitalis of atrial flutter to fibrillation.

Based on a paper read at the University of Padua on June 15, 1963, on the occasion of a visit of the Harveian Society of London.

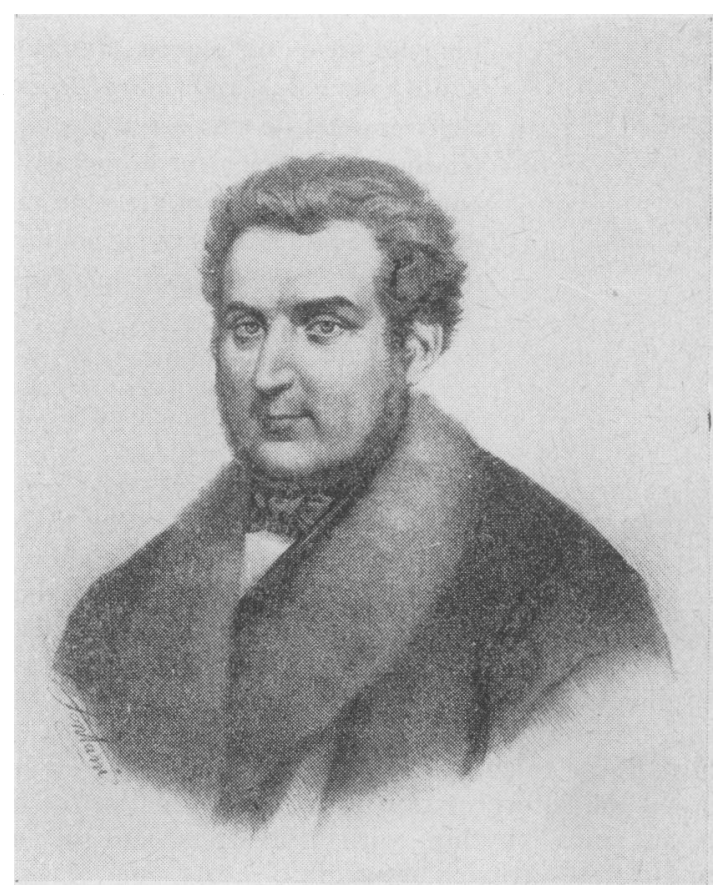

FIG. I.-Carlo Matteucci (I81 I-68). Lithograph of 1853. By courtesy of the Wellcome Historical Medical Library.

\section{Digitalis Intoxication}

This leads to the clinical aspects and, in view of its practical importance, the increasingly appreciated value of the ECG in the early recognition of existing or impending digitalis intoxication may be mentioned in the first place. Of 2,000 consecutive ECG's recently recorded in our hospital group and sent for reporting, 597 referred to 348 patients who had digitalis within the fortnight preceding at least one ECG. ECG signs highly suggestive of overdigitalization were found in at least $10 \%$ of the 348 patients. It is hoped to publish elsewhere a more detailed account of this observation. Several causes are responsible for this high incidence. It is often not realized how greatly patients vary in their requirement and 
PHysiologiE. - Sur le courant électrique ,les muscles des animaux vivants ou récenunent tués. Extrait d'une Iuttre de M. Ca. Marreuccr à M. de Humboldt.

“ $1^{\circ}$. Les sigues du courant propre de la grenouille, démontrés parr le " galvanomètre, augmentent au même instrument dans l'acte de la contrac" tion. n

\section{8}

" $2^{\circ}$. Le courant électrique musculaire, que désormais j’appellerai cou" rant musculaire, se trouve dảns toutes les masses musculaires, quel que n soit l'animal. n

" J'ai pris des muscles pectoraux de pigeon, des muscles du dos d'un lapin, des coeurs de pigeon, des muscles de tanche, des morceaux d'une anguille à laquelle j’avais enlevé la peau. J'ai composé des piles avec ces différents muscles de manière à faire toucher l'intérieur du muscle avec la surface tendineuse de l'élément musculaire voisin. Dans tous les cas, j’ai obtenu un courant qui va de lintérieur du muscle à la surface : les signes de ce courant, qui augmentent avec le nombre des éléments, cessent après un certain temps d'autant plus court, que l'animal est plus élevé dans l'échelle.

\section{FIG. 2.-Matteucci, C. Beginning, and part referring to heart muscle, of his paper, "Sur le courant élec- trique des muscles des animaux vivants ou récemment tués'. 1843 .}

tolerance of this drug, also that old patients require and tolerate only smaller doses than young ones (see also Wollheim, 1954/55; Scherf, 1958). Another common cause is the mistaken belief that an optimum dose of digitalis must reduce the ventricular rate. This is a misapplication, to patients with normal rhythm, of conditions prevailing in atrial fibrillation with a high ventricular rate. A further source of error is the misinterpretation as atrial fibrillation of a basic sinus rhythm with numerous and often multiform ventricular ectopic beats, or of an ectopic ventricular tachycardia, themselves due to overdosage. But in atrial fibrillation, too, a similar mistake is often made by ignoring ectopic ventricular arrhythmias induced by overdigitalization and misinterpreting the rhythm as just a high ventricular rate which must be reduced-so more digitalis is given, a vicious circle. In these and similar cases one glance at an ECG reveals the true state of affairs. Atrial arrhythmias as a sign of digitalis intoxication have increasingly been recognized of late, and most physicians are familiar with paroxysmal atrial tachycardia with atrio-ventricular block as the most characteristic variety. What is perhaps not so commonly appreciated is the fact that changes in the shape of $\mathbf{P}$ waves may be the first sign of impending digitalis overdosage.

\section{Electrolyte Disturbances}

Another important aspect is the relation between electrocardiography and electrolytes. It must stressed from the start that these relationso extremely complex, since the ECG is determined not by one electrolyte, but by the relatess between several, $\mathrm{K}^{+}, \mathrm{Na}^{+}$and $\mathrm{Ca}^{++}$in particullar. With this reservation it may be said that hyp kalæmia presents fairly easily identifiable featurg, of which the depression of S-T junctions a id distortion of S-T segments, followed by high upright $U$ waves, are the most characteristic ${ }^{2}$ the fully developed picture (Fig. 4). Such ECG? are also found in patients with normal serum $\mathrm{K}^{+}$(see below). The cardiologist will encounter these ECG's particularly in potassium depletion due to digitalization and concurrent diure sicc treatment, especially when carried out over longer periods. In renal disease it assumes practical importance, amongst other conditions, in the event of hæmodialysis. Wiih this procedure some disturbance of the electrolyte equilibrium is often unavoidable and it is therefore advisable not 20 digitalize fully before hæmodialysis is undertaken. Hyperkalæmia presents also a typical picture, with high symmetrical $T$ waves as an eandy diagnostic sign (Fig. 5). It is found in the early stages of acute nephritis, also in the final stages $6 f$ chronic nephritis where it is often associated with hypocalcæmia. This combination results in lengthening of the Q-T interval due to the calcium deficiency, combined with high peaked पT waves indicative of hyperkalæmia. These changes are reversible by hæmodialysis, and intravenous 

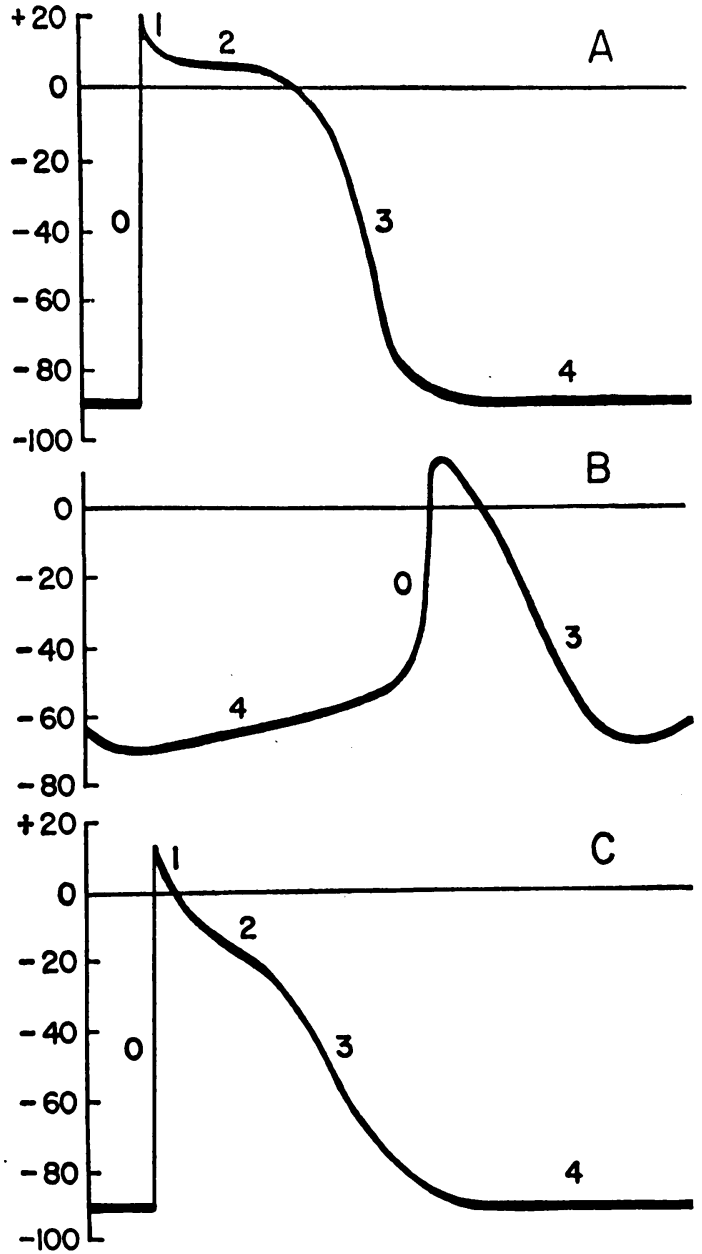

FIG. 3.-Schematic records of transmembrane action potentials recorded from ventricle (A), sinoatrial node (B), and atrium (C). Sweep velocity in B one-half that in $\mathrm{A}$ and $\mathrm{C}$. Ordinate scale in $\mathrm{mV}$. (See text for discussion.) From Hoffman and Cranefield, 'Electrophysiology of the Heart', McGraw-Hill Book Co., New York, Toronto and London. 1960.

infusions of sodium chloride, bicarbonate or lactate, and glucose and insulin.

With the now universal use of direct writing instruments, electrocardiography is also providing valuable help in the control of correction of severe hypokalæmia by the intravenous injection of $\mathrm{KCl}$ : here, the ECG is the best guide to indicate the moment when to stop the injection in order to avoid hyperkalæmia. Similar considerations apply to the treatment of ectopic arrhythmias by intravenous procaine amide or quinidine, where the ECG indicates the moment of change of rhythm or shows warning signs of drug toxicity.
ECG features suggesting hypo- or hyperkalæmia need not correspond to the potassium concentration in the serum (see Fig. 4b). Findings agree well in cases with marked abnormalities, namely, $\mathrm{K}^{+}$concentrations over 6.7 and below $2.3 \mathrm{mEq}$. (Dreifus and Pick, 1956). In many cases, however, discrepancies are found and their explanation is still controversial. The main argument revolves round two main theories, viz. that the ECG is determined by the absolute concentration of $\mathrm{K}^{+}$ in the myocardial fibres, or that the deciding factor is the intra-extracellular $\mathrm{K}^{+}$gradient. In practice it seems reasonable to argue that a suggestive ECG should be considered as a warning sign even with normal serum concentrations. This holds good particularly for patients on digitalis and diuretics if an ECG shows features pointing to hypokalæmia.

\section{Differential Diagnosis}

The help of the ECG in the differential diagnosis between myocardial infarction, acute pericarditis and pulmonary embolism should not be forgotten. A correct diagnosis is of great importance, not only because of the greatly different prognosis, but also as some cases of pericarditis require steroid treatment, for example, the variety due to disseminated lupus erythematosus, to be suspected particularly when occurring in a young female; occasionally also the pericarditis of the post-myocardial syndrome.

A normal twelve-lead ECG may also be of great diagnostic importance. As with so many biological methods, the distinction between normal and abnormal in borderline cases can be most difficult, and it is significant that, as recently as I961, an admirable book on the statistical evaluation of this problem was published by Simonson. A personal observation may also illustrate this point. A 45-year-old man, admitted shortly after a sudden attack of excruciating central chest pain, was considered to be such a typical case of myocardial infarction that anticoagulants were started before an ECG was taken. A record the following day was entirely normal, and a chest film showed spontaneous pneumothorax which soon developed into a hæmopneumothorax. This was a pardonable mistake since spontaneous pneumothorax without any dyspnœa and presenting only with violent sudden central chest pain is very unusual. The patient made a complete recovery.

\section{Vectorcardiography}

In conclusion, vectorcardiography may be mentioned as one further recent development of electrocardiography. The basic principle is simple: two leađs standing at right angles to one 

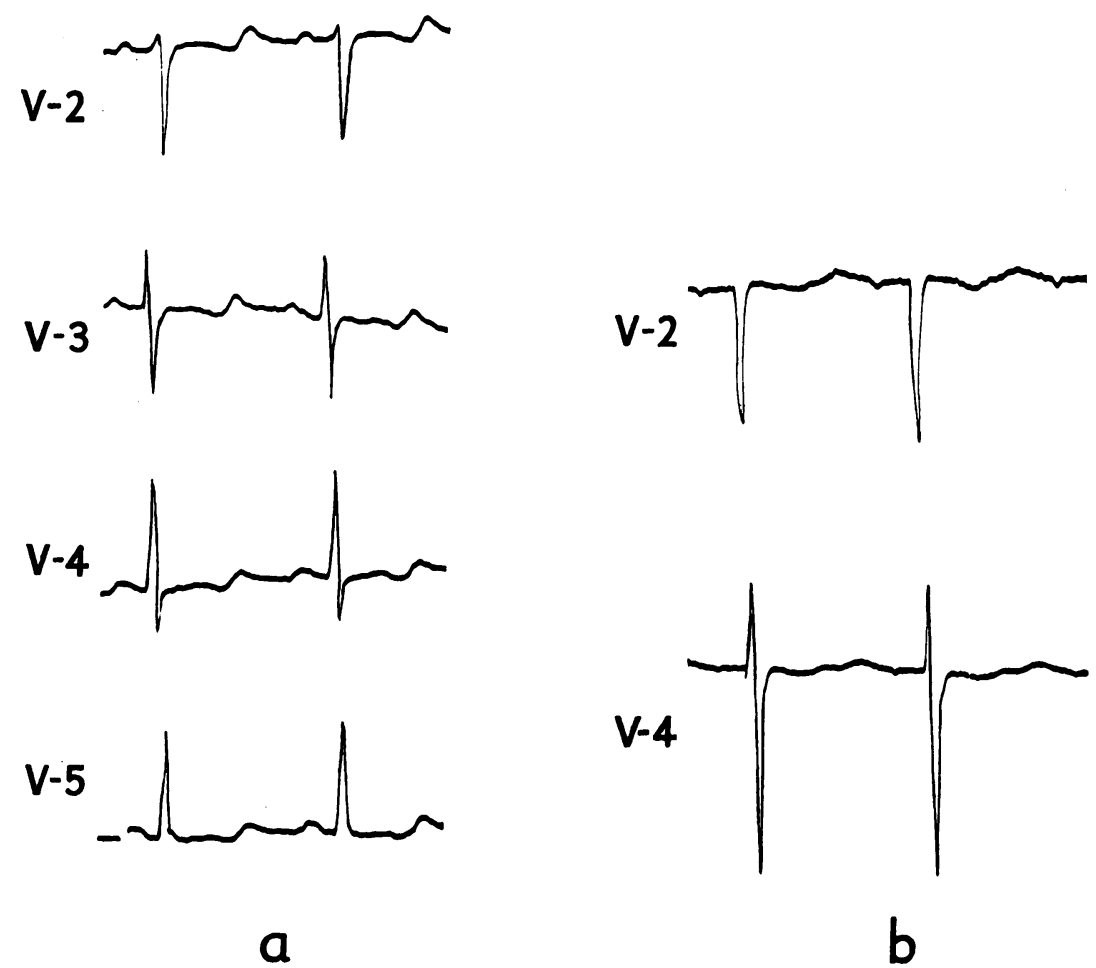

FIG. 4.-Hypokalæmia. (a) $\mathrm{K}^{+}=3.6 \mathrm{mEq} / 1 . \mathrm{Na}^{+}=126 \mathrm{mEq} / 1 . \mathrm{Cl}^{\prime}=88.9 \mathrm{mEq} / 1$. (b) From a woman of 87 with diabetic ketosis. Serum electrolytes normal.

another are recorded simultaneously with a cathode ray oscillograph, which makes it possible to record directly the projection of the threedimensional electrical changes in the heart onto one plane-frontal, sagittal, or horizontal, depending on the placement of the electrodesinstead of onto one line, that is, a lead of a conventional ECG. These vectorcardiograms consist of closed loops. Though the basic principle is simple, the theory as well as the clinical interpretation of vectorcardiograms are very complex. Despite the enormous amount of work the method is still in its experimental stage, and it is impossible to state at present whether it will materially complement, let alone ever replace, lead electrocardiography. There are two reasons for men- tioning this method in the present context: in the first place, no talk on recent aspects of elect5cardiography could afford to omit at least $\frac{3}{3}$ a brief reference to this development. Secondly ${ }^{-i t}$ provides a welcome opportunity of pay tribute to another distinguished Italian, Luciaio Pozzi of Florence, for his outstanding work on this complicated subject (Pozzi, I96r).

With all modesty, when surveying the develơpment between Matteucci's first report in 1843 \&े an electrical phenomenon in hearts and Pozs's work published in 1961, we are, I think, justifed in claiming some progress in this field; and we should, I am sure, thank the country of our hosts, Italy, for the contribution its scientists have made to achieve it.

\section{REFERENCES}

Dreifus, L. S., and Pick, A. (1956): A Clinical Correlative Study of the Electrocardiogram in Electrolyte Imbalate, Circulation, 14, 815.

HoffMan, B. F., and Cranefield, P. F. (1960): 'Electrophysiology of the Heart'. New York, Toronto and Lond McGraw-Hill Book Co.

LiNG, G., and GERARD, R. W. (1949): The Normal Membrane Potential of Frog Sartorius Fibers, f. cell. comp. Phys逐l.,

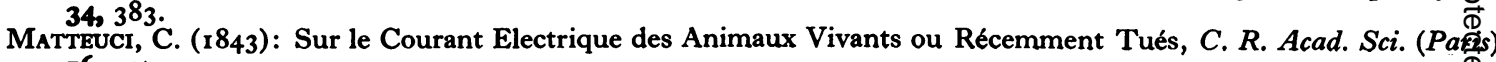
16, 197. 
McEwen, L. M. (1956): The Effect on the Isolated Rabbit Heart of Vagal Stimulation and its Modification by Cocaine, Hexamethonium and Ouabain, F. Physiol. (Lond.), r31, 678.

Perry, W. L. M., and Reinert, H. (1954): The Action of Cardiac Glycosides on Autonomic Ganglia, Brit. Y. Pharmacol, 9. 324 .

PozzI, L. (1961): 'Basic Principles in Vector Electrocardiography'. London: Kimpton.

SCHERF, D. (1958): Digitalis Therapy, Dis. Chest, 33, 93.

Simonson, E. (1961): 'Differentiation between Normal and Abnormal in Electrocardiography'. St. Louis: C. V. Mosby.

Trautwein, W., Kassebaum, D. G., Nelson, R. M., and Hecht, H. H. (1962): Electrophysiological Study of Human Heart Muscle, Circulat. Res., 10, 306.

WolLhIIM, E. (1954-55): Alterserscheinungen an Herz und Kreislauf und ihre Behandlung, Regensburg. \%b. drztl. Fortbild., 4, 115 .

Woodbury, J., LeE, J., Brady, A. J., and Merendino, K. A. (1957): Transmembrane Potentials from the Human Heart, Circulat. Res., 5, 179.

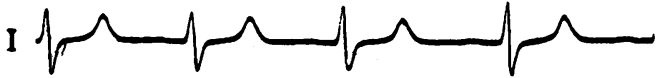

VI

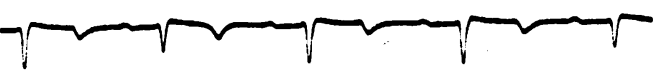

II

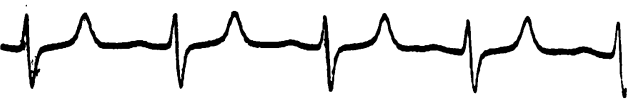

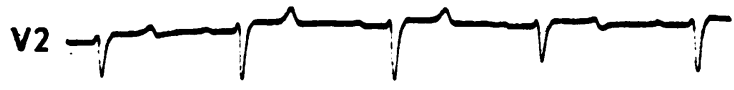

III

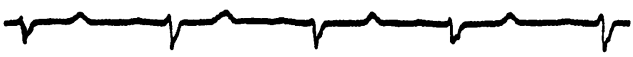

ANR
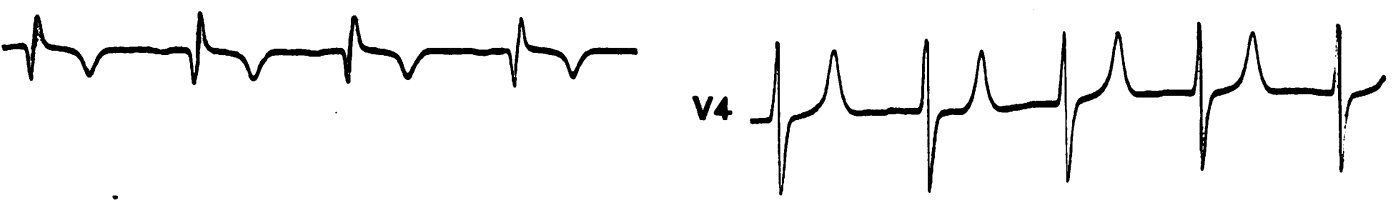

AVL

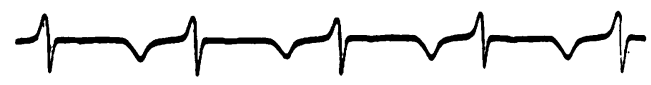

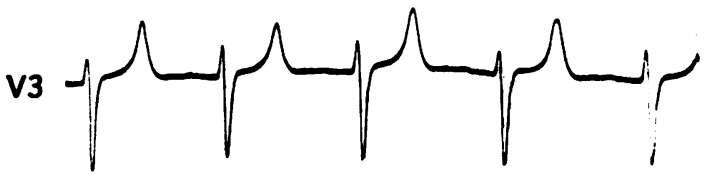
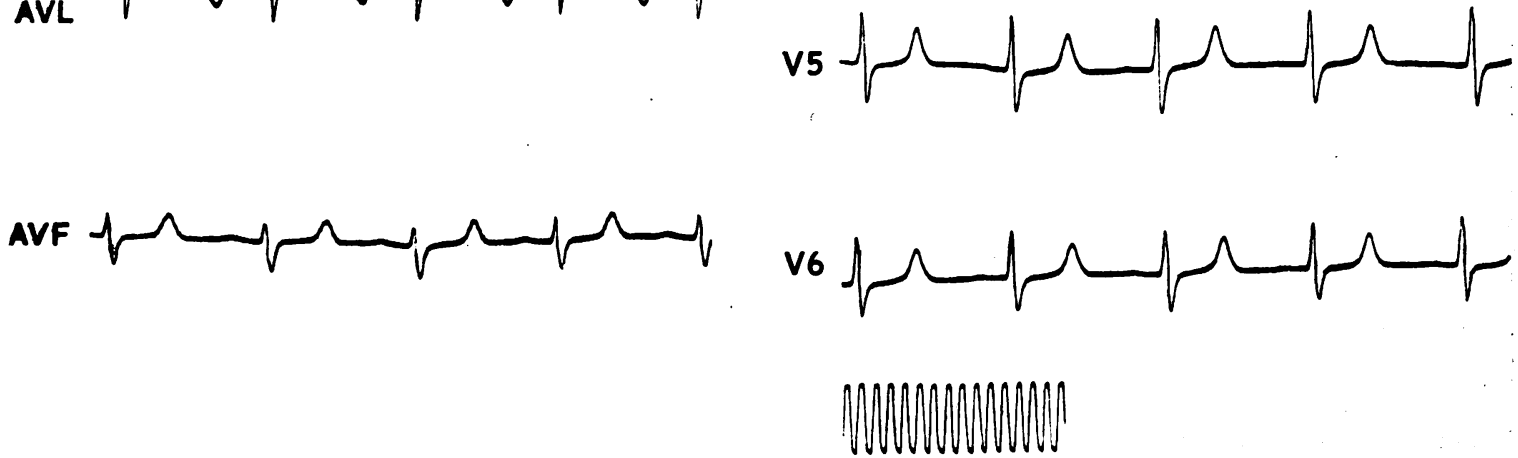

FIG. 5.-Hyperkalæmia. From a girl of 10 with acute nephritis. Serum $\mathrm{K}^{+}=8.9 \mathrm{mEq} / \mathrm{l}$. 